\title{
REVIEW
}

\section{A Practical Approach to Glucose Abnormalities in Cystic Fibrosis}

Gregory C. Jones · Christopher A. R. Sainsbury

Received: September 12, 2016 / Published online: October 17, 2016

(c) The Author(s) 2016. This article is published with open access at Springerlink.com

\section{ABSTRACT}

Cystic fibrosis is a common genetic condition and abnormal glucose handling leading to cystic fibrosis-related diabetes (CFRD) is a frequent comorbidity. CFRD is mainly thought to be the result of progressive pancreatic damage resulting in beta cell dysfunction and loss of insulin secretion. Whilst Oral Glucose Tolerance Testing is still recommended for diagnosing CFRD, the relationship between glucose abnormalities and adverse outcomes in $\mathrm{CF}$ is complex and occurs at stages of dysglycaemia occurring prior to diagnosis of diabetes by World Health Organisation criteria. Insulin remains the mainstay of treatment of CF-related glucose abnormalities but the timing of insulin commencement, optimum insulin regime and targets of glycaemic control are not clear. These complexities are compounded by common issues with nutritional status, need for

Enhanced content To view enhanced content for this article go to http://www.medengine.com/Redeem/ 1F07F06021932850.

G. C. Jones $(\bowtie)$ - C. A. R. Sainsbury

Diabetes Department, Gartnavel General Hospital, 1053 Great Western Road, Glasgow G12 0YN, UK e-mail: g.jones3@nhs.net enteral feeding, steroid use and high disease burden on CF patients.

Keywords: Cystic

fibrosis-related

fibrosis;
diabetes;

Cystic

Hypoglycaemia

\section{INTRODUCTION}

Cystic fibrosis (CF) is a common life-limiting autosomal recessive condition with the highest prevalence in populations with Northern European ancestry. The disease is caused by gene mutation causing defective function of a chloride channel-the cystic fibrosis transmembrane conductance regulator (CFTR)—which is vital for mucociliary clearance in the airways [1]. Cystic fibrosis impacts several organ systems including the liver, skin sweat glands and pancreas, but its classical impact on morbidity and mortality is via bronchiectasis, airways obstruction and progression to respiratory failure.

Abnormalities of glucose metabolism are an important co-morbidity of CF. Classically, progressive loss of beta cell function in $\mathrm{CF}$ 
leads to abnormal glucose levels and progression to cystic fibrosis-related diabetes (CFRD) [2-4]. The development of glucose abnormalities is recognised to herald a clear increase in morbidity and mortality in patients with $\mathrm{CF}$, leading to a focus on identifying and controlling disordered glucose metabolism in CF $[5,6]$.

The management of CFRD is complex and importantly it differs significantly from that of type 1 and type 2 diabetes. Management of CFRD requires a multidisciplinary approach to attempt to ensure the best possible clinical outcome, whilst minimising treatment-associated adverse events.

This article explores the pathophysiology, diagnosis and clinical impact of glucose abnormalities in CF and discusses the approach to treatment of this challenging problem.

\section{Compliance with Ethics Guidelines}

This article is based on previously conducted studies and does not involve any new studies of human or animal subjects performed by any of the authors.

\section{PATHOPHYSIOLOGY}

CFRD is primarily characterisable as a defect of insulin release resulting from the secretions blocking pancreatic ducts, autodigestion, oxidative stress and destructive fibrotic pancreatic disease that ultimately destroys islet cell function [2-4]. Pancreatic beta cell function and first phase insulin secretion have been shown to be reduced in CFRD when compared to normal glucose tolerance (NGT) patients with CF where no difference is observed in insulin resistance [7]. Patients with CF also have more rapid small bowel glucose absorption further exacerbating postprandial glucose excursions [8].

Patients with CF have also been shown to have decreased GLP-1 activity compared to normal controls, which may contribute to glucose abnormalities [9]. CF is a complex multisystem disease, and multiple defects in nutritional status and metabolism also contribute to observed glucose abnormalities. Table 1 summarises these defects and their consequences for glucose metabolism.

\section{EPIDEMIOLOGY}

CFRD is clinically and pathophysiologically distinct from either type 1 or type 2 diabetes. It occurs in children and young adults with a median age at onset of 20 years. It appears to develop earlier in female than male patients [10]. Of 158 adults (categorised by WHO OGTT criteria or physician insulin initiation) over 16 years of age attending a CF service in the UK, 51 (32.3\%) had CFRD, 24 (15.2\%) had impaired fasting glucose or impaired glucose tolerance, and $83(52.5 \%)$ had normal glucose tolerance [11]. CFRD appears to be more common in patients who are homozygous for the most common CFTR gene mutation, $\Delta$ F508.10 [3]. Ketoacidosis is rare but can occur if CFRD goes untreated or in the presence of significant intercurrent infection [12]. As the age at which CFRD and type 1 diabetes usually present overlaps, it is important to remember that patients with CF can also develop type 1 diabetes.

The recent history of CF has been one of greatly improved survival. Improvements in physiotherapy and drugs to clear mucus from the lungs and aggressive treatment of infection, combined with pancreatic exocrine 
Table 1 Factors impacting on glucose regulation in CF

\begin{tabular}{lll}
\hline System & Defect & Impact on metabolism \\
\hline Endocrine pancreas & Reduced insulin secretion & Postprandial hyperglycaemia \\
& Reduced glucagon secretion & Progression to CFRD \\
Exocrine pancreas & Reduced pancreatic enzyme production & Malabsorption of fat, protein and carbohydrate \\
Gut & Malabsorption of fat and protein & Rapid postprandial glucose excursions \\
& Rapid glucose absorption & Low glucose preprandial \\
& Less active GLP-1 & Reduced insulin and increased glucagon secretion \\
Liver & Liver insulin insensitivity & Hyperglycaemia \\
& Reduced glycogen storage & Reduced response to hypoglycaemia \\
& Cirrhosis & \\
Fat/muscle & Decreased fat stores & Increased insulin sensitivity \\
& Decreased muscle mass & \\
Adrenal & Insulin sensitivity & Stress hyperglycaemia \\
& Cortisol response to intercurrent infections & Steroid related hyperglycaemia \\
\hline
\end{tabular}

supplements and enhanced nutrition, have all contributed to significant improvements in morbidity and mortality in patients with cystic fibrosis. In Europe a significant reduction in potential years life lost (PYLL) for patients between 0 and 30 years old has been described. In males, the standardised PYLL decreased from 14.65 (11.37-17.93) lost years per million persons per year in 1994 to 7.49 (6.14-8.84) in 2010 [13]. In Canada, median survival age increased from 31.9 years $(95 \% \mathrm{CI}$ 28.3-35.2 years) in 1990 to 49.7 years (95\% CI 46.1-52.2 years) in the 5-year window ending in 2012 [14]. As patients with CF live longer it is likely therefore that the prevalence of CFRD will increase.

\section{DIAGNOSIS}

The onset of CFRD cannot reliably be detected symptomatically, with around $2 / 3$ of patients asymptomatic at diagnosis [15]. Given the potential impact of CFRD on morbidity and mortality, a reliable biochemical screening test for CFRD is vital. There is general agreement between national and international societies that CFRD should be diagnosed using the standard $75 \mathrm{~g}$ Oral Glucose Tolerance Test (OGTT) with the general recommendation that this should be carried out annually in all patients from childhood [16, 17]. Use of the OGTT in the diagnosis of CFRD does however have a number of disadvantages. First, it is a time-consuming investigation for patients and staff to perform. Furthermore, the OGGT was primarily developed as a way of predicting risk of microvascular and macrovascular complications of hyperglycaemia, and as such it does not necessarily predict the risks and complications associated with dysglycaemia in CF. The response of measured glucose to an oral glucose challenge is especially variable in 
patients with CF. In one study glucose tolerance improved [from normal to impaired glucose tolerance (IGT) or from CFRD to normal or IGT] in $18 \%$ of patients over 4 years whilst 19\% worsened in category over the same time period [18]. Crucially, early CFRD is classically characterised by postprandial glucose excursions secondary to loss of first phase insulin. In order to have an optimal chance of detecting this abnormality a $1 \mathrm{~h}$ glucose estimation would be required during OGTT, and indeed it has been shown that $1 \mathrm{~h}$ glucose levels are a better predictor of decline in pulmonary function than $2 \mathrm{~h}$ levels during GTT [19].

Whilst HbA1c is now accepted as a diagnostic tool within the field of diabetes, it is difficult to interpret as a diagnostic test for CFRD. Relatively brief periods of postprandial hypoglycaemia with low normal pre-meal glucose levels have the potential to lead to reassuringly normal HbA1c values. Studies assessing the consistency of $\mathrm{HbA1c}$ as a measure of mean blood glucose in CFRD and HbA1c have shown conflicting results $[20,21]$. CFRD is additionally associated with a lower than normal red cell lifespan, which could reduce diagnostic utility [22]. In one prospective study an HbA1c of $>46 \mathrm{mmol} / \mathrm{mol}$ showed a positive predictive value of $50 \%$ when compared with OGGT [15]. In another study elevated $\mathrm{HbA} 1 \mathrm{c}>42 \mathrm{mmol} / \mathrm{mol}$ was seen in only $38 \%$ of patients with diabetes, confirming a poor sensitivity as a diagnostic test in CFRD [7]. If HbA1c is to have utility, lower levels will need to be considered as clinically important. An $\mathrm{HbA} 1 \mathrm{c} \geq 40 \mathrm{mmol} / \mathrm{mol}$ has been proposed as a diagnostic level for CFRD screening and is suggested to reduce the need for an OGTT by $50.7 \%$ [23]. A systematic review of screening tests for CFRD agreed that the sensitivity of
HbA1c is too low to recommended it as a diagnostic test [24].

Given that pulmonary consequences of CFRD are known to occur when only $1 \mathrm{~h}$ postprandial glucose is elevated when measured during an OGTT, there is theoretical merit in using $1 \mathrm{~h}$ levels measured by capillary blood glucose (CBG) monitoring or continuous glucose monitoring when performing this investigation [25-28].

Our local practice is to recommend annual OGTT for all patients from age 10 years and $1 \mathrm{~h}$ postprandial CBG monitoring in patients where clinically indicated by declining lung function, recurrent infection or weight loss. Table 2 shows a summary of diagnostic guidelines.

\section{IMPACT ON PROGNOSIS}

Abnormalities of glucose metabolism have a clear association with morbidity and mortality in CF patients. It is less clear whether hyperglycaemia or insulin deficiency have a causal relationship with poor outcomes or are simply markers of more advanced or complicated disease.

Worsening lung function is clearly associated with glucose abnormalities, and a decline in pulmonary function appears to be related to the severity of glucose intolerance and insulin deficiency [18]. Patients with CFRD have more episodes of infection and have higher rates of colonisation with important pathogenic organisms such as BurkholderiaCepacia and Aspergillus suggesting impaired immunity [29]. It has been suggested that an association between poor lung function and dysglycaemia may be more important in females [30].

In a UK registry study of 5892 patients with CF the presence of diabetes was an independent 
Table 2 Suggested criteria for diagnosis of CFRD (Adapted from ADA guidelines [16])

\begin{tabular}{ll}
\hline Patient status & $\begin{array}{c}\text { Suggested diagnostic glucose level (mmol/l) (all CBG results to be confirmed } \\
\text { by laboratory measurement) }\end{array}$ \\
Healthy outpatients & 75 G OGTT fasting $\geq 7$ or $2 \mathrm{~h} \geq 11.1$ \\
& $\begin{array}{l}\text { Random }>11.1 \text { on } 2 \text { measures with osmotic symptoms, declining weight or } \\
\text { lung function }\end{array}$ \\
Enteral tube feeding & $\geq 11.1$ during feed on 2 occasions \\
Acute illness or steroid use & Fasting $\geq 7$ \\
& Random $\geq 11.1$ on 2 occasions over $48 \mathrm{~h}$ \\
\hline
\end{tabular}

risk factor for death (hazard ratio 1.31 (95\% CI 1.03-1.67)] [31]. Registry data from the US show that in patients with $\mathrm{CF}$, controlling for other risk factors, diabetes is associated with a $55 \%$ increase in 5-year mortality [32].

These consistent associations between insulinopenicdysglycaemia and adverse outcome suggest correcting glucose abnormalities with insulin or insulin secretagogues may confer benefit.

Whilst the the primary focus in CFRD is on lung function and nutritional status, it is important to remember that, as with all types of diabetes mellitus, effective screening for microvascular complications is required. Compared to patients with type 1 diabetes patients with CFRD have a similar incidence of microvascular disease with a lower prevalence of retinopathy and a higher prevalence of microalbuminuria [33]. Screening for microvascular complications is likely to increase in importance with increasing longevity of patients with CFRD.

\section{TREATMENT OF HYPERGLYCAEMIA}

Unlike other forms of diabetes where control of glucose is primarily to prevent microvascular and macrovascular complications, the main goal in CFRD is prevention and improvement of declining respiratory function and nutritional status. Several small non-randomised studies, retrospective reviews and case series have suggested a benefit of insulin in both reducing the decline of lung function and weight loss. These studies use a variety of insulins with various levels of glycaemia and clinical triggers for patient selection [34-37]. We have reported retrospective, observational data from our unit, which suggest that introducing insulin at the stage of impaired glucose tolerance seems to ameliorate loss of lung function and increase weight [38]. One open-label randomised study attempted to assess the impact on clinical outcomes of preprandial insulin treatment compared to repaglinide and placebo in patients with CFRD but no fasting hyperglycaemia. There was no change in decline in lung function or infections in the insulin group at 12 months, but there was a significant improvement in BMI. It was felt that the short duration of the study made it unlikely that changes in lung function would have been detected [39]. A systematic review performed by the National Institute for Health Research concluded that insulin appears beneficial in CFRD and probably at the IGT stage [24].

Hypoglycaemia is an obvious potential risk when using insulin in CF patients. 
Hypoglycaemia can be observed in CF patients even before they have treatment for dysglycaemia, perhaps suggesting a mismatch between the increased late insulin secretion and rapid carbohydrate absorption [40]; $6.1 \%$ of CBG measurements performed in hospitalised patients with CF who were treated with insulin were found to be in the hypoglycaemia range ( $<4.0 \mathrm{mmol} / \mathrm{l})$. Hypoglycaemia was also found to be associated with a significantly higher rate of readmission or death over the 3.5-year follow-up period $(P=0.03)$ [41]. This is a higher rate of hypoglycaemia than that previously reported in the general population of inpatients with diabetes [42]. Hypoglycaemia in CF patients treated with insulin has also been associated with high levels of loss of awareness of hypoglycaemia, which may reflect loss of glucagon response or high exposure to hypoglycaemic range glucose [38]. It is therefore important to balance the potential benefit of insulin use in CF with the burden and harm of hypoglycaemia.

Continuous subcutaneous insulin infusion (CSII) by pump would seem in theory to offer significant potential advantages of flexibility and avoidance of hypoglycaemia, which could be of particular benefit in CFRD. Despite this CSII is not commonly used in patients with CFRD, perhaps reflecting increased cost or a feeling that CSII may be too much of a burden to patients already requiring intensive medical intervention [43].

There have been some small studies of insulin secretagogues showing reductions in glucose levels in CFRD; however none have shown significant benefit to important outcomes of lung function or weight $[39,44]$. We do not presently recommended the use of insulin secretagogues in CFRD.

It is our local practice to consider insulin initiation where hyperglycaemia (glucose $>11.1 \mathrm{mmol} / \mathrm{l}$ ) is detected either by screening or clinical monitoring triggered by clinical concern such as where the patients has poor nutritional status, declining lung function or recurrent lung infection. We favour the use of the prandial insulin bolus initially in the majority of cases for reasons of flexibility and as postprandial hyperglycaemia is usually the primary abnormality. We add basal insulin when fasting glucose becomes abnormal or bolus requirements become high.

There is insufficient evidence to be dogmatic about what glycaemic target should be aimed for in patients with CFRD. The ADA recommend achieving the same target $\mathrm{CBG}$ levels as those with type 1 diabetes (preprandial 4.4-7.2 mmol/l and postprandial $<10 \mathrm{mmol} / \mathrm{l})[16,45]$. This seems a reasonable goal, and patients should be encouraged to perform CBG testing regularly including postprandially if possible. Table 3 suggests a guideline for management of glucose abnormalities in CF with insulin.

\section{IMPACT OF OTHER THERAPIES}

Nutritional status is of great importance in CF patients who have both increased resting energy expenditure and increased loss of calories through malabsorption and in whom cachexia is known to worsen outcome [46]. Optimising nutritional status is therefore an important goal, which has been shown to improve the ability to undertake normal daily activities [47]. Patients with CF are therefore recommended to take a high calorie diet (usually $120-150 \%$ of the daily recommended intake for age) [16]. To maintain high calorific intake enteral tube feeding (ETF) is commonly utilised and is thought to improve outcome [48]. Schedules for tube feeding vary and take into account the patient's schedule and other treatments, 
Table 3 Suggested approach (based on or local practice) to insulin treatment in CFRD

\begin{tabular}{|c|c|c|c|}
\hline & Reason to commence & Starting dose & Optimal target glucose \\
\hline Prandial bolus insulin & $\begin{array}{l}\text { 1-2 } \mathrm{h} \text { postprandial } \\
\text { glucose }>11.1 \mathrm{mmol} / 1 \\
\text { With clinical indication }^{\mathrm{a}}\end{array}$ & 0.5 units per $10 \mathrm{~g} \mathrm{CHO}$ & $\begin{array}{l}1-2 \mathrm{~h} \text { postprandial glucose } \\
<10 \mathrm{mmol} / \mathrm{l}\end{array}$ \\
\hline Basal insulin & $\begin{array}{l}\text { If fasting }>7.2 \mathrm{mmol} / 1 \text { or if } \\
\text { boluses needed greater } \\
\text { than } 1.5 \text { units per } 10 \mathrm{~g} \\
\mathrm{CHO}\end{array}$ & $\begin{array}{l}\text { Add } 0.1 \text { unit per kg either } \\
\text { long acting insulin (e.g., } \\
\text { glargine) morning or } \\
\text { intermediate acting (e.g., } \\
\text { insulatard) night if fasting } \\
\text { high adding morning if } \\
\text { bolus requirements high }\end{array}$ & $\begin{array}{l}\text { Fasting }<7.2 \mathrm{mmol} / 1 \\
\text { Premeal }<7.2 \mathrm{mmol} / 1\end{array}$ \\
\hline Enteral tube feeding insulin & $\begin{array}{l}6-8 \mathrm{~h} \text { feed with } \\
\text { glucose }>11.1 \mathrm{mmol} / \mathrm{l} \\
4-6 \mathrm{~h} \text { feed with } \\
\text { glucose }>11.1 \mathrm{mmol}\end{array}$ & $\begin{array}{l}\text { Add insulatard } 0.5 \text { units per } \\
10 \mathrm{~g} \mathrm{CHO} \\
\text { Add actrapid } 0.5 \text { units per } \\
10 \mathrm{~g} \text { CHO }\end{array}$ & $\begin{array}{l}\text { During or end of feed } \\
\quad<10 \mathrm{mmol} / 1\end{array}$ \\
\hline
\end{tabular}

Existing and required dose of insulin may double during acute illness and steroid therapy

a Osmotic symptoms, weight loss, recurrent lung infection, or decline in lung function

making evidence-based guidelines used in other settings for control of glucose during ETF less applicable [49]. Our experience suggests that liaisoning between the diabetes team and specialist dieticians is crucial when planning ETF. In CF patients ETF is often performed at home and overnight, and timing of feeds can vary from 4-12 h. Variation in the timing and tolerability of ETF can make choosing the optimum insulin to maximise energy conservation from the feed challenging. Choice of insulin should be made by matching the duration of insulin action to the agreed enteral feeding regimen. Dosing and insulin type can then be altered dependent on CBG readings before, during, and after ETF starts. Overnight CBG monitoring during ETF will disturb sleep and is therefore particularly burdensome to patients.

Use of steroids (usually prednisolone or methylprednisolone) has been common in patients with CF and can cause transient hyperglycaemia or worsen glucose control in existing CFRD. It has been reported that over $50 \%$ of CFRD patients who have been admitted to hospital will have had at least one course of steroid treatment [50]. There is little evidence to guide management of hyperglycaemia related to steroid use in the general population let alone in CFRD. National guidelines suggest enhanced CBG monitoring and the use of insulin to correct hyperglycaemia [51]. We recommend CBG monitoring of fasting and postprandial glucose in all CF patients started on steroids.

\section{SUMMARY}

Glucose abnormalities related to CF pose unique challenges to both diabetes and respiratory teams. The close associations between worsening dysglycaemia and poor outcome suggest benefit from insulin replacement therapy, but the time to start treatment and desired CBG levels remain 
controversial. Insulin therapy has significant potential to cause harm-especially by inducing hypoglycaemia. At present we recommend a pragmatic multidisciplinary approach to managing this complex area. We suggest insulin use targeting postprandial glucose excursions, initiated when risks of declining lung function and nutritional status are high. We use postprandial CBG measurements to guide insulin dosing along with pre-prandial and fasting CBG measurement to guard against hypoglycaemia. Further data would be welcomed on the optimum timing of insulin initiation and on the glycaemic targets that would best prevent decline in lung function.

\section{ACKNOWLEDGMENTS}

No funding or sponsorship was received for this study or publication of this article. All named authors meet the International Committee of Medical Journal Editors (ICMJE) criteria for authorship for this manuscript, take responsibility for the integrity of the work as a whole, and have given final approval for the version to be published.

Disclosures. Gregory C. Jones and Christopher A. R. Sainsbury have nothing to disclose.

Compliance with Ethics Guidelines. This article is based on previously conducted studies and does not involve any new studies of human or animal subjects performed by any of the authors.

Open Access. This article is distributed under the terms of the Creative Commons AttributionNonCommercial 4.0 International License (http://creativecommons.org/licenses/by-nc/4. $0 /$ ), which permits any noncommercial use, distribution, and reproduction in any medium, provided you give appropriate credit to the original author(s) and the source, provide a link to the Creative Commons license, and indicate if changes were made.

\section{REFERENCES}

1. Elborn JS. Cystic fibrosis. Lancet [Internet]. 2016; http://dx.doi.org/10.1016/S0140-6736(16)00576-6. Accessed 1 Sept 2016.

2. Ode KL, Moran A. New insights into cystic fibrosis-related diabetes in children. Lancet Diabetes Endocrinol. 2013;1:52-8.

3. Street ME, Spaggiari C, Ziveri MA, Rossi M, Volta C, Viani I, et al. Insulin production and resistance in cystic fibrosis: effect of age, disease activity, and genotype. J Endocrinol Invest. 2012;35:246-53.

4. Ntimbane T, Comte B, Mailhot G, Berthiaume Y, Poitout V, Prentki M, et al. Cystic fibrosis-related diabetes: from CFTR dysfunction to oxidative stress. Clin Biochem Rev. 2009;30:153-77.

5. Lewis C, Blackman SM, Nelson A, Oberdorfer E, Wells D, Dunitz J, et al. Diabetes-related mortality in adults with cystic fibrosis. Role of genotype and sex. Am J Respir Crit Care Med. 2015;191:194-200.

6. Bismuth E, Laborde K, Taupin P, Velho G, Ribault V, Jennane $F$, et al. Glucose tolerance and insulin secretion, morbidity, and death in patients with cystic fibrosis. J. Pediatr. 2008;152:540-5, 545.e1.

7. Mohan K, Miller H, Dyce P, Grainger R, Hughes R, Vora J, et al. Mechanisms of glucose intolerance in cystic fibrosis. Diabet Med. 2009;26:582-8.

8. Frase LL, Strickland AD, Kachel GW, Krejs GJ. Enhanced glucose absorption in the jejunum of patients with cystic fibrosis. Gastroenterology. 1985;88:478-84.

9. Hillman M, Eriksson L, Mared L, Helgesson K, Landin-Olsson M. Reduced levels of active GLP-1 in patients with cystic fibrosis with and without diabetes mellitus. J Cyst Fibros. 2012;11:144-9.

10. Finkelstein SM, Wielinski CL, Elliott GR, Warwick WJ, Barbosa J, Wu SC, et al. Diabetes mellitus associated with cystic fibrosis. J Pediatr. 1988;112:373-7.

11. Adler AI, Gunn E, Haworth CS, Bilton D. Characteristics of adults with and without cystic 
fibrosis-related diabetes. Diabet Med. 2007;24:1143-8.

12. Eenkhoorn V, Van den Driessche A, Van Gaal L, Desager K, De Block C. Diabetic keto-acidosis as a presentation of cystic fibrosis-related diabetes: a case report. J Diabetes Complications. 2011;25: 137-41.

13. Quintana-Gallego E, Ruiz-Ramos M, Delgado-Pecellin I, Calero C, Soriano JB, Lopez-Campos JL. Mortality from cystic fibrosis in Europe: 1994-2010. Pediatr Pulmonol. 2016;51: 133-42.

14. Stephenson AL, Tom M, Berthiaume $Y$, Singer LG, Aaron SD, Whitmore GA, et al. A contemporary survival analysis of individuals with cystic fibrosis: a cohort study. Eur Respir J. 2015;45:670-9.

15. Lanng S, Hansen A, Thorsteinsson B, Nerup J, Koch C. Glucose tolerance in patients with cystic fibrosis: five year prospective study. BMJ. 1995;311:655-9.

16. Moran A, Brunzell C, Cohen RC, Katz M, Marshall BC, Onady G, et al. Clinical care guidelines for cystic fibrosis-related diabetes: a position statement of the American Diabetes Association and a clinical practice guideline of the Cystic Fibrosis Foundation, endorsed by the Pediatric Endocrine Society. Diabetes Care. 2010;33:2697-708.

17. Cystic Fibrosis Trust-Consensus documents [Internet]. [cited 2016 Sep 1]. https://www. cysticfibrosis.org.uk/the-work-we-do/clinical-care/ consensus-documents. Accessed 1 Sept 2016.

18. Milla CE, Warwick WJ, Moran A. Trends in pulmonary function in patients with cystic fibrosis correlate with the degree of glucose intolerance at baseline. Am J Respir Crit Care Med. 2000;162:891-5.

19. Brodsky J, Dougherty S, Makani R, Rubenstein RC, Kelly A. Elevation of 1-hour plasma glucose during oral glucose tolerance testing is associated with worse pulmonary function in cystic fibrosis. Diabetes Care. 2011;34:292-5.

20. Godbout A, Hammana I, Potvin S, Mainville D, Rakel A, Berthiaume $Y$, et al. No relationship between mean plasma glucose and glycated haemoglobin in patients with cystic fibrosis-related diabetes. Diabetes Metab. 2008;34: 568-73.

21. Brennan AL, Gyi KM, Wood DM, Hodson ME, Geddes DM, Baker EH. Relationship between glycosylated haemoglobin and mean plasma glucose concentration in cystic fibrosis. J Cyst Fibros. 2006;5:27-31.
22. Wagener JS, McNeill GC, Taussig LM, Corrigan JJ, Lemen R. Ferrokinetic and hematologic studies in cystic fibrosis patients. Am J Pediatr Hematol Oncol. 1983;5:153-60.

23. Burgess JC, Bridges N, Banya W, Gyi KM, Hodson ME, Bilton D, et al. HbA1c as a screening tool for cystic fibrosis related diabetes. J Cyst Fibros. 2016;15:251-7.

24. Waugh N, Royle P, Craigie I, Ho V, Pandit L, Ewings $P$, et al. Screening for cystic fibrosis-related diabetes: a systematic review. Health Technol. Assess. 2012;16:iii-iv, 1-179.

25. Franzese A, Valerio G, Buono P, Spagnuolo MI, Sepe A, Mozzillo E, et al. Continuous glucose monitoring system in the screening of early glucose derangements in children and adolescents with cystic fibrosis. J Pediatr Endocrinol Metab. 2008;21:109-16.

26. Dobson L, Sheldon CD, Hattersley AT. Conventional measures underestimate glycaemia in cystic fibrosis patients. Diabet Med. 2004;21:691-6.

27. Wilkinson JD, Craigie IP, Allison G, Gallacher C, Crocker J, Kent S. Investigating suspected CF-related diabetes mellitus utilising serial capillary blood glucose profiling. J Cyst Fibros. 2008; 7:S83.

28. Jefferies C, Solomon M, Perlman K, Sweezey N, Daneman D. Continuous glucose monitoring in adolescents with cystic fibrosis. J Pediatr. 2005;147:396-8.

29. Marshall BC, Butler SM, Stoddard M, Moran AM, Liou TG, Morgan WJ. Epidemiology of cystic fibrosis-related diabetes. J Pediatr. 2005;146:681-7.

30. Sims EJ, Green MW, Mehta A. Decreased lung function in female but not male subjects with established cystic fibrosis-related diabetes. Diabetes Care [Internet]. Am Diabetes Assoc; 2005; http:// care.diabetesjournals.org/content/28/7/1581.short. Accessed 1 Sept 2016.

31. Chamnan P, Shine BSF, Haworth CS, Bilton D, Adler AI. Diabetes as a determinant of mortality in cystic fibrosis. Diabetes Care. 2010;33:311-6.

32. Liou TG, Adler FR, Fitzsimmons SC, Cahill BC, Hibbs JR, Marshall BC. Predictive 5-year survivorship model of cystic fibrosis. Am J Epidemiol. 2001;153:345-52.

33. van den Berg JMW, Morton AM, Kok SW, Pijl H, Conway SP, Heijerman HGM. Microvascular complications in patients with cystic 
fibrosis-related diabetes (CFRD). J Cyst Fibros. 2008;7:515-9.

34. Dobson L, Hattersley AT, Tiley S, Elworthy S, Oades PJ, Sheldon CD. Clinical improvement in cystic fibrosis with early insulin treatment. Arch Dis Child. 2002;87:430-1.

35. Lanng S, Thorsteinsson B, Nerup J, Koch C. Diabetes mellitus in cystic fibrosis: effect of insulin therapy on lung function and infections. Acta Paediatr. 1994;83:849-53.

36. Nousia-Arvanitakis S, Galli-Tsinopoulou A, Karamouzis M. Insulin improves clinical status of patients with cystic-fibrosis-related diabetes mellitus. Acta Paediatr. 2001;90:515-9.

37. Rolon MA, Benali K, Munck A, Navarro J, Clement A, Tubiana-Rufi $\mathrm{N}$, et al. Cystic fibrosis-related diabetes mellitus: clinical impact of prediabetes and effects of insulin therapy. Acta Paediatr. 2001;90:860-7.

38. Drummond RS, Ross E, Bicknell S, Small M, Jones GC. Insulin therapy in patients with cystic fibrosis related diabetes mellitus: benefit, timing of initiation and hypoglycaemia. Practical Diabetes International. Wiley Online Library. 2011;28:177-82.

39. Moran A, Pekow P, Grover P, Zorn M, Slovis B, Pilewski J, et al. Insulin therapy to improve BMI in cystic fibrosis-related diabetes without fasting hyperglycemia: results of the cystic fibrosis related diabetes therapy trial. Diabetes Care. 2009;32:1783-8.

40. Haliloglu B, Gokdemir Y, Atay Z, Abali S, Guran T, Karakoc F, et al. Hypoglycemia: An unrecognized problem in cystic fibrosis (CF) patients unmasked by continues glucose monitorisation (CGM). Eur Respir J Eur Respir Soc. 2014;44:P1216.

41. Jones GC, Chong ZM, Gilmour J, Matheson C, MacGregor G, Sainsbury CAR. Patterns and Impact of Hypoglycemia, Hyperglycemia, and Glucose Variability on Inpatients with Insulin-Treated Cystic Fibrosis-Related Diabetes. Diabetes Ther. [Internet]. 2016. doi:10.1007/s13300-016-0194-7. Accessed 1 Sept 2016.

42. Jones GC, Casey H, Perry CG, Kennon B, Sainsbury CAR. Trends in recorded capillary blood glucose and hypoglycaemia in hospitalised patients with diabetes. Diabetes Res Clin Pract. 2014;104:79-83.
43. Scheuing N, Badenhoop K, Borkenstein M, Konrad $\mathrm{K}$, Lilienthal E, Laubner $\mathrm{K}$, et al. Why is insulin pump treatment rarely used in adolescents and young adults with cystic fibrosis-related diabetes? Pediatr Diabetes. 2015;16:10-5.

44. Culler FL, McKean LP, Buchanan CN, Caplan DB, Meacham LR. Glipizide treatment of patients with cystic fibrosis and impaired glucose tolerance. J Pediatr Gastroenterol Nutr. 1994;18:375-8.

45. Checking Your Blood Glucose [Internet]. American Diabetes Association. [cited 2016 Aug 31]. http:// www.diabetes.org/living-with-diabetes/treatmentand-care/blood-glucose-control/checking-your-blood -glucose.html?referrer=https://www.google.co.uk/. Accessed 1 Sept 2016.

46. Sharma R, Florea VG, Bolger AP, Doehner W, Florea $\mathrm{ND}$, Coats AJ, et al. Wasting as an independent predictor of mortality in patients with cystic fibrosis. Thorax. 2001;56:746-50.

47. Levy LD, Durie PR, Pencharz PB, Corey ML. Effects of long-term nutritional rehabilitation on body composition and clinical status in malnourished children and adolescents with cystic fibrosis. J Pediatr. 1985;107:225-30.

48. White H, Morton AM, Conway SP, Peckham DG. Enteral tube feeding in adults with cystic fibrosis; patient choice and impact on long term outcomes. J Cyst Fibros. 2013;12:616-22.

49. Glycaemic management during the inpatient enteral feeding of stroke patients with diabetes (Aug 2012)-Diabetes UK [Internet]. [cited 2016 Jul 31]. https://www.diabetes.org.uk/About_us/Whatwe-say/Specialist-care-for-children-and-adults-andcomplications/Glycaemic-management-during-theinpatient-enteral-feeding-of-stroke-patients-withdiabetes/. Accessed 1 Sept 2016.

50. Rasouli N, Seggelke S, Gibbs J, Hawkins RM, Casciano ML, Cohlmia E, et al. Cystic fibrosis-related diabetes in adults: inpatient management of 121 patients during 410 admissions. J Diabetes Sci Technol. 2012;6:1038-44.

51. Management of hyperglycaemia and steroid (glucocorticoid) therapy (October 2014)_Diabetes UK [Internet]. [cited 2016 Aug 29]. https://www. diabetes.org.uk/About_us/What-we-say/Specialistcare-for-children-and-adults-and-complications/ Management-of-hyperglycaemia-and-steroid-gluco corticoid-therapy-October-2014/. 